\title{
Wastewater Treatment by Novel Polyamide/Polyethylenimine Nanofibers with Immobilized Laccase
}

\author{
Milena Maryšková ${ }^{1, *}\left(\mathbb{0}\right.$, Markéta Schaabová ${ }^{2}$, Hana Tománková ${ }^{2} \oplus$, Vít Novotný ${ }^{2}$ and \\ Miroslava Rysová 2 (D) \\ 1 Faculty of Mechatronics, Technical University of Liberec, 46001 Liberec, Czech Republic \\ 2 Institute for Nanomaterials, Technical University of Liberec, 46001 Liberec, Czech Republic; \\ marketa.schaabova@tul.cz (M.S.); hana.tomankova@tul.cz (H.T.); novotnvt@gmail.com (V.N.); \\ miroslava.rysova@tul.cz (M.R.) \\ * Correspondence: milena.maryskova@tul.cz
}

Received: 17 January 2020; Accepted: 17 February 2020; Published: 21 February 2020

check for updates

\begin{abstract}
Endocrine-disrupting chemicals are highly resistant organic compounds, commonly occurring in the aquatic environment, that can interfere with the endocrine system of animals and humans, causing serious chronic diseases. In recent decades, enzymes from oxidoreductases have been studied for their potential to degrade these compounds effectively. In order to use such enzymes repeatedly, it is necessary to ensure their insolubility in water, a method termed enzyme immobilization. We developed novel polyamide/polyethylenimine (PA/PEI) nanofibers as a promising support material for the immobilization of various biomolecules. Our nanofibers are highly suitable due to a unique combination of mechanical endurance provided by polyamide 6 and their affinity toward biomolecules, ensured by numerous PEI amino groups. Enzyme laccase was successfully immobilized onto PA/PEI nanofibers using a simple and fast method, providing exceptional activity and stability of the attached enzyme. We then tested the degradation ability of the PA/PEI-laccase samples on a highly concentrated mixture of endocrine-disrupting chemicals in real wastewater with adjusted $\mathrm{pH}$. The results indicate that the samples were a suitable material for wastewater treatment by degrading a highly concentrated mixture of bisphenol A, $17 \alpha$-ethinylestradiol, triclosan, and diclofenac, in real wastewater effluent.
\end{abstract}

Keywords: wastewater treatment; endocrine-disrupting chemicals; nanofibers; laccase; immobilization

\section{Introduction}

The persistence of anthropogenic contaminants (ACs) in the aquatic environment has attracted a lot of attention among government agencies and scientists around the globe. The level of contamination has reached such a level that ACs are detectable in water bodies all over the world [1], mostly in the range of $\mathrm{ng} / \mathrm{L}$ to $\mathrm{mg} / \mathrm{L}$ [2]. The incapability of living organisms to perfectly metabolize these compounds leads to increasing bioaccumulation in the ecosystem [3]. The most significant and problematic of ACs are pharmaceuticals (e.g., diclofenac, ibuprofen, $17 \alpha$-ethinylestradiol), food industry derivatives (e.g., bisphenol A), personal care products (e.g., triclosan), agricultural products, and pesticides and narcotics, of which many compounds have been recognized as endocrine-disrupting chemicals (EDCs) or contaminants with considerable endocrine-disrupting potency. EDCs are associated with animaland human-health problems, such as hormonal imbalance, alterations in the sex ratios of some animal species, neurological disorders, changes in behavior, metabolism disorders, cellular toxicity, and genotoxicity, leading to cancer or immunological problems [4]. 
Present wastewater treatment technologies are not efficient enough to ensure satisfactory elimination of EDCs from water bodies; hence, optimization and redesign of conventional physicochemical removal methods is now a major environmental concern worldwide [5]. As an alternative to conventional progressive technologies, such as advanced oxidation (e.g., ozonation, UV oxidation) or treatment with powdered activated carbon, bioremediation methods are based on biological processes exploiting mainly microorganisms, fungi, or plants. Instead of living organisms, the use of enzymes separated from their cells provides a number of advantages, including lack of toxicity and potential metabolic products, high catalytic activity, substrate specificity, shorter reaction time, and mild reaction conditions [6].

In order to utilize enzymes for industrial applications, it is necessary to immobilize them, thereby enabling repeated or long-term use. In addition, enzyme immobilization usually improves pH and thermal stability by conserving tertiary structures and active sites, which also results in reduced financial costs [7,8]. Many types of enzyme supports exist, including nanoparticles [9,10], nanotubes [11], mesoporous materials [12], sponges [13], and nanofibrous materials [14-16].

In this study, our aim is to develop a nanofiber blend matrix combining two polymers: the robust, mechanically durable, low-cost, and easily prepared polyamide 6 (PA6), and branched polyethylenimine (PEI), which is rich in free amino groups suitable for covalent attachment of an enzyme. We chose to use a nanofiber mat, mainly as it is safe to handle, easy to prepare, and has wide applications in a range of filtration systems. Though PEI has often been used as a spacer arm providing biomolecule-friendly surface modification of various synthetic materials [17-19], the combination of PA6 and PEI is unique. Rather than surface modification, we aim to incorporate PEI directly into the nanofibrous structure using a blend polymer solution, ensuring that numerous amino groups remain available for further covalent attachment of enzymes and other potential biomolecules.

Finally, we aim to immobilize laccase from Trametes versicolor onto the polyamide/polyethylenimine (PA/PEI) mat and test these PA/PEI-laccase samples for their ability to degrade a highly concentrated mixture of endocrine-disrupting chemicals (bisphenol A (BPA), 17 $\alpha$-ethinylestradiol (EE2), triclosan (TSC), and diclofenac (DCF)) in real effluent wastewater.

\section{Materials and Methods}

\subsection{Reagents}

T. versicolor laccase (>10 U/mg, powder), 2,2'-azino-bis (3-ethylbenzothiazoline-6-sulphonic acid) (ABTS; $>98 \%$ ), sodium periodate (ACS reagent, $\geq 99.8 \%$ ), methyl orange (MO; ACS reagent, dye content $85 \%$ ), bisphenol A (BPA; $\geq 99 \%$ ), 17 $\alpha$-ethinylestradiol (EE2; $\geq 98 \%$ ), triclosan (TCS; analytical standard), diclofenac (DCF, analytical standard), and polyethylenimine (PEI; branched, Mw 25,000) were all obtained from Sigma-Aldrich (St. Louis, MO, USA). Pelleted polyamide 6 (PA6; Ultramid ${ }^{\circledR}, \mathrm{Mw}^{\mathrm{N}}$ $37,000 \mathrm{~g} / \mathrm{mol}$ ) was obtained from BASF (Ludwigshafen, Germany). All other reagents used were of analytical grade.

\subsection{Preparation and Characterization of the Nanofiber Matrix}

The polymer blend electrospinning solution was prepared by a two-step method. In the first step, PA6 pellets were dissolved in a mixture of acetic acid and formic acid $(65 / 35, v / v)$ to reach a final concentration of $12 \mathrm{wt} \%$. Subsequently, polyethylenimine solution was added and the blend was gently stirred overnight. The final PEI concentration in the polymer blend solution was $2.15 \mathrm{wt} \%$. The polymer solution was electrospun using NanospiderTM NS 1 WS500U (Elmarco Ltd., Liberec, Czech Republic) equipment. The distance between electrodes was firmly set to $175 \mathrm{~mm}$, and the voltage applied was $15 / 60 \mathrm{kV}$. The electrospun nanofiber sheets containing approximately $15 \%$ of the dry weight of PEI required no further stabilization or modification.

Structural differences between pristine PA/PEI nanofibers and nanofibers with immobilized laccase (PA/PEI-laccase) were assessed using Carl Zeiss ULTRA Plus (Zeiss, Oberkochen, Germany) scanning 
electron microscope (SEM). The images obtained were analyzed using VEGA TC software in order to assess average fiber diameter by averaging the values of 100 individual measurements.

\subsection{Characterization of Amino Groups}

The amount of available primary amino groups was estimated using the method described in reference [20]. In short, methyl orange (MO) is an acid dye that binds with amino groups and can subsequently be removed by bases. Firstly, the nanofiber samples were incubated in $0.05 \%(w / v)$ MO solution in $0.01 \mathrm{M} \mathrm{pH} 4.7$ phosphate buffer for $1 \mathrm{~h}$. Next, the unbound MO was thoroughly washed with deionized water (DIW) and 0.1 M sodium carbonate was added to the samples in order to release all bound MO. The number of amino groups was estimated spectrophotometrically by reading the absorbance at $465 \mathrm{~nm}$ and using equation from the study of Hartwig et al. [20].

\subsection{Measurement of Laccase Activity}

Laccase catalytic activity was determined at $420 \mathrm{~nm}$ according to reference [21,22] using a BioTech Synergy HTX microplate reader (BioTech Instruments Inc., Winooski, VT, USA). Catalytic activity of laccase solution was measured in $160 \mu \mathrm{L}$ Mcllvaine's buffer at pH 3 containing $20 \mu \mathrm{L}$ of the stock enzyme solution and the same volume of $0.5 \mathrm{mM}$ ABTS. The activity of the PA/PEI-laccase samples was measured by adding the sample into $3.6 \mathrm{~mL}$ of the buffer followed by $400 \mu \mathrm{L}$ of $0.5 \mathrm{mM}$ ABTS. The reaction tube was constantly shaken in order to avoid adsorption of the ABTS product into the nanofibers and to insure sufficient distribution of the oxidation product within the whole volume. Samples of the product were taken at selected time intervals and measured under the conditions described above. Finally, the activity yield of PA/PEI-laccase samples using the optimized method was calculated as the activity of immobilized laccase divided by the enzymatic activity of stock laccase solution used for the immobilization.

\subsection{Laccase Immobilization}

T. versicolor laccase was immobilized onto the PA/PEI nanofibers via oxidation of the enzyme and subsequent covalent attachment. A range of parameters, including buffer concentration and $\mathrm{pH}$, concentration of laccase and the oxidation agent $\left(\mathrm{NaIO}_{4}\right)$, and oxidation and immobilization time, were examined in order to establish the most effective immobilization method. Preliminary experiments identified the optimal immobilization process temperature as $4{ }^{\circ} \mathrm{C}$ and the most convenient mode of agitation providing uniform enzyme solution distribution as orbital shaking at $150 \mathrm{rpm}$. The optimal volume of laccase solution used for immobilization onto nanofiber samples of $1.5 \mathrm{~cm}$ in diameter was $300 \mu \mathrm{l}$. The optimal immobilization process based on the results presented required a $10 \mathrm{mg} / \mathrm{mL}$ laccase stock solution to be oxidized via $1 \mathrm{mM} \mathrm{NaIO}_{4}$ for $30 \mathrm{~min}$ and 30-min immobilization of $2 \mathrm{mg} / \mathrm{mL}$ laccase solution at $\mathrm{pH} 7$ buffer. After each immobilization process, the samples were washed with citrate-phosphate buffer (McIlvaine's buffer) at pH 3 until no laccase activity was detected in the washings, following which activity of the immobilized laccase was determined. Effect of the studied parameters on the activity of PA/PEI-laccase was confirmed using one-factor analysis of variance (ANOVA, $p<0.05$ ). The differences between the data were performed using a multiple comparison test.

\subsection{Storage Stability and Reusability of Immobilized Laccase}

Immobilized laccase (PA/PEI-laccase) was incubated in DIW at $4{ }^{\circ} \mathrm{C}$ in order to assess storage stability. Two replicate samples were taken at selected time points $(7,14,21$, and 30 days) and their enzyme activity measured. Reusability of the PA/PEI-laccase nanofibers was determined by measuring enzyme activity as described in Section 2.4 over several catalytic cycles. The samples were removed from the ABTS mixture between measurements and thoroughly washed with fresh buffer at $\mathrm{pH} 3$. Reusability is an important indicator for the strength of enzyme-support bond and usually represents more informative data than a single activity measurement. An activity increase within a number of 
catalytic cycles might suggest either gradual enzyme activation by ABTS catalysis or ABTS product adsorption into the nanofiber support within the first cycles and its gradual saturation.

\subsection{Degradation of Endocrine-Disrupting Chemicals}

Degradation of a mixture of BPA, EE2, TCS, and DCF with an initial concentration of $10 \mathrm{mg} / \mathrm{L}$ of each contaminant was performed in three different water systems: (i) deionized water (DIW), (ii) pretreated wastewater via ultrafiltration, and (iii) wastewater infused with $2.5 \%(v / v)$ of Mcllvaine's buffer at pH 7 (buffer concentration based on preliminary experiments in parallel studies). Table 1 shows standard chemical analysis of the wastewater effluent. (The presence of organic pollutants was not assessed). One PA/PEI-laccase sample was immersed into $5 \mathrm{~mL}$ of EDCs mixture in a glass vial and incubated for $20 \mathrm{~h}$ at room temperature under mild agitation $(80 \mathrm{rpm})$. Subsequently, samples were removed and $10 \mu \mathrm{L}$ of $10 \%$ sodium azide was added in order to inhibit possible laccase molecules leaked from the nanofiber carrier.

Table 1. Chemical analysis of ultrafiltered wastewater.

\begin{tabular}{cccc}
\hline Analyte & Conc. $(\mathrm{mg} / \mathrm{L})$ & Analyte & Conc. $(\mathrm{mg} / \mathrm{L})$ \\
\hline Fluoride & 0.16 & $\mathrm{Cr}$ & $<0.001$ \\
Chloride & 213 & $\mathrm{Cu}$ & $<0.001$ \\
Nitrate & 9.5 & $\mathrm{Fe}$ & 0.003 \\
Nitrite & $<0.05$ & $\mathrm{~K}$ & 74.8 \\
Sulfate & 9.5 & $\mathrm{Mg}$ & 21.3 \\
$\mathrm{TOC}$ & 6.2 & $\mathrm{Mn}$ & $<0.001$ \\
$\mathrm{Ag}$ & 0.0019 & $\mathrm{Na}$ & 119 \\
$\mathrm{Al}$ & 0.035 & $\mathrm{Ni}$ & 0.002 \\
$\mathrm{Be}$ & $<0.001$ & $\mathrm{~Pb}$ & $<0.01$ \\
$\mathrm{Ca}$ & 127 & $\mathrm{~V}$ & $<0.01$ \\
$\mathrm{Co}$ & $<0.002$ & $\mathrm{Zn}$ & 0.014 \\
\hline
\end{tabular}

EDCs' (BPA, EE2, TCS, and DCF) concentration was measured using a Dionex Ultimate 3000 high-pressure liquid chromatograph (HPLC, Thermo Fisher Scientific, Waltham, MA, USA), equipped with a LPG-3400SD quaternary gradient pump, SR-3000 solvent rack, WPS-3000TSC autosampler, TCC-3000SD column compartment, DAD-3000 detector, and Phenomenex Kinetex F5 core-shell column (Torrance, CA, USA, length $150 \mathrm{~mm}$, internal diameter $4.6 \mathrm{~mm}$ ). The aqueous component of the mobile phase consisted of $10 \mathrm{mM}$ phosphoric acid in $5 \%(v / v)$ acetonitrile, while the organic component consisted of $10 \mathrm{mM}$ phosphoric acid in a mixture of $90 \%$ acetonitrile and $10 \%$ methanol $(v / v)$.

\section{Results}

\subsection{Nanofiber Characterization}

The novel PA/PEI nanofibers prepared for this study excelled in several parameters. First, the nanofiber sheets were easy to handle due to their mechanical properties, provided by presence of PA6, and thickness, while PEI ensured the presence of multiple primary amino groups together with excellent nanofiber wettability.

PA/PEI nanofibers (Figure 1a) had a surface density of $7-7.5 \mathrm{~g} / \mathrm{m}^{2}$ and an average fiber diameter of ca. $100 \mathrm{~nm}$. The PA/PEI-laccase sample (Figure 1b) had a noticeably different surface morphology to the smooth pristine PA/PEI nanofibers, being somewhat grainy and containing thinner fibrous structures. 


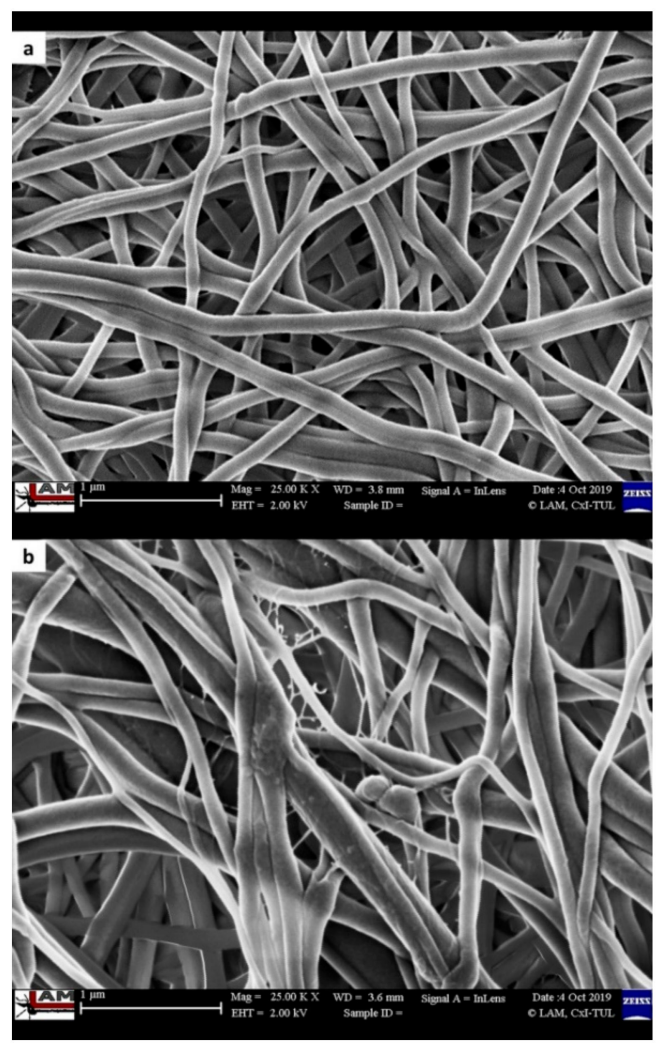

Figure 1. Comparison of pristine polyamide 6/polyethylenimine (PA/PEI) nanofibers (a) and PA/PEI with immobilized T. versicolor laccase (b).

\section{Quantification of Amino Groups}

While PA6 nanofibers possessed only $16.96 \pm 0.61 \mathrm{nmol} / \mathrm{mg}$ of free amino groups, branched PEI increased the concentration in PA/PEI nanofibers almost 40 -fold to $670 \pm 57.2 \mathrm{nmol} / \mathrm{mg}$ (Figure 2a). The difference was further displayed by the amount of attached MO molecules, which gave the samples a distinct orange hue (Figure $2 b$ ).
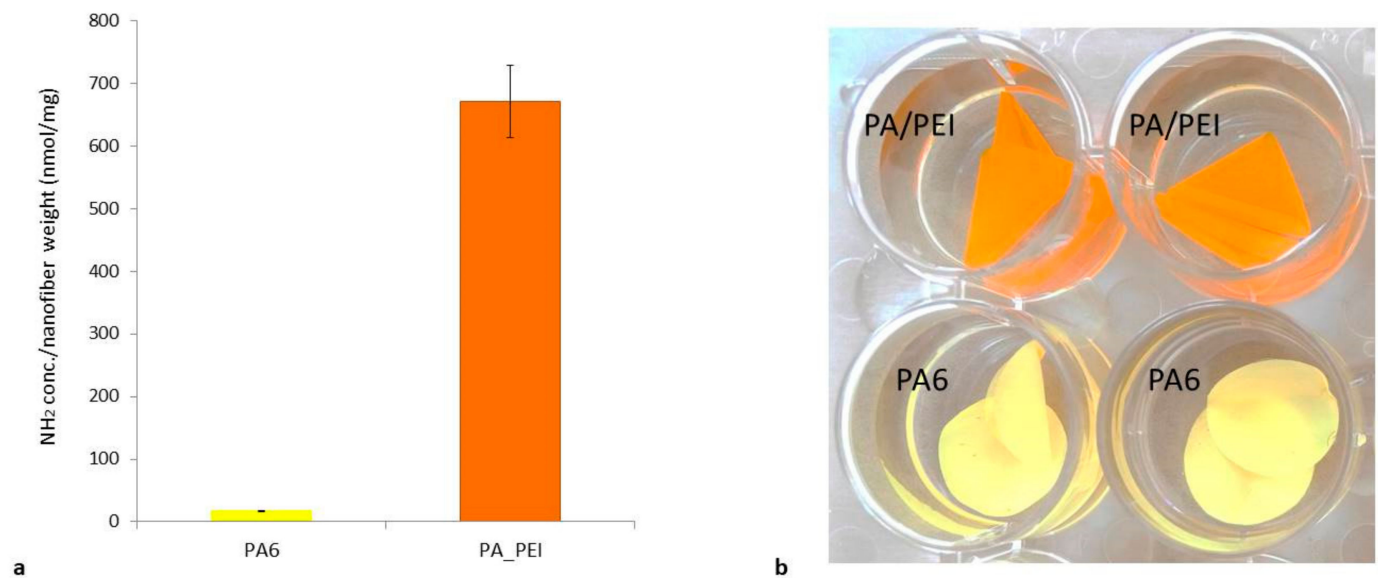

Figure 2. Quantification of available amino groups of polyamide 6 (PA6) and polyamide 6/polyethylenimine (PA/PEI) nanofibers (a). Color difference according to the amount of methyl orange $(\mathrm{MO})$ attached to the nanofibers $(\mathbf{b})$. 


\subsection{Optimal Conditions for Laccase Immobilization}

\subsubsection{Effect of Buffer Concentration and $\mathrm{pH}$ on the Immobilization of Laccase onto PA/PEI Nanofibers}

Buffer concentration and $\mathrm{pH}$ mainly influence the total charge of enzyme molecules and the supporting material, thereby affecting emerging bonds between laccase and PA/PEI nanofibers. In general, each type of binding requires different conditions, as the optimal $\mathrm{pH}$ for laccase adsorption may be different from those for creation of a covalent bond. In this study, enzyme activity increased with lower buffer concentration (Figure 3a). Considering both catalytic activity and reusability of the immobilized laccase, 20\% McIlvaine's buffer proved to be the best at providing an optimal combination of both parameters. In terms of optimal $\mathrm{pH}$, a neutral $\mathrm{pH}$ was preferable for immobilization of the oxidized laccase (Figure 3c). This corresponds to previous studies, where neutral or somewhat alkaline $\mathrm{pH}$ (range 7-10) proved optimum for formation of Schiff bases [23,24].
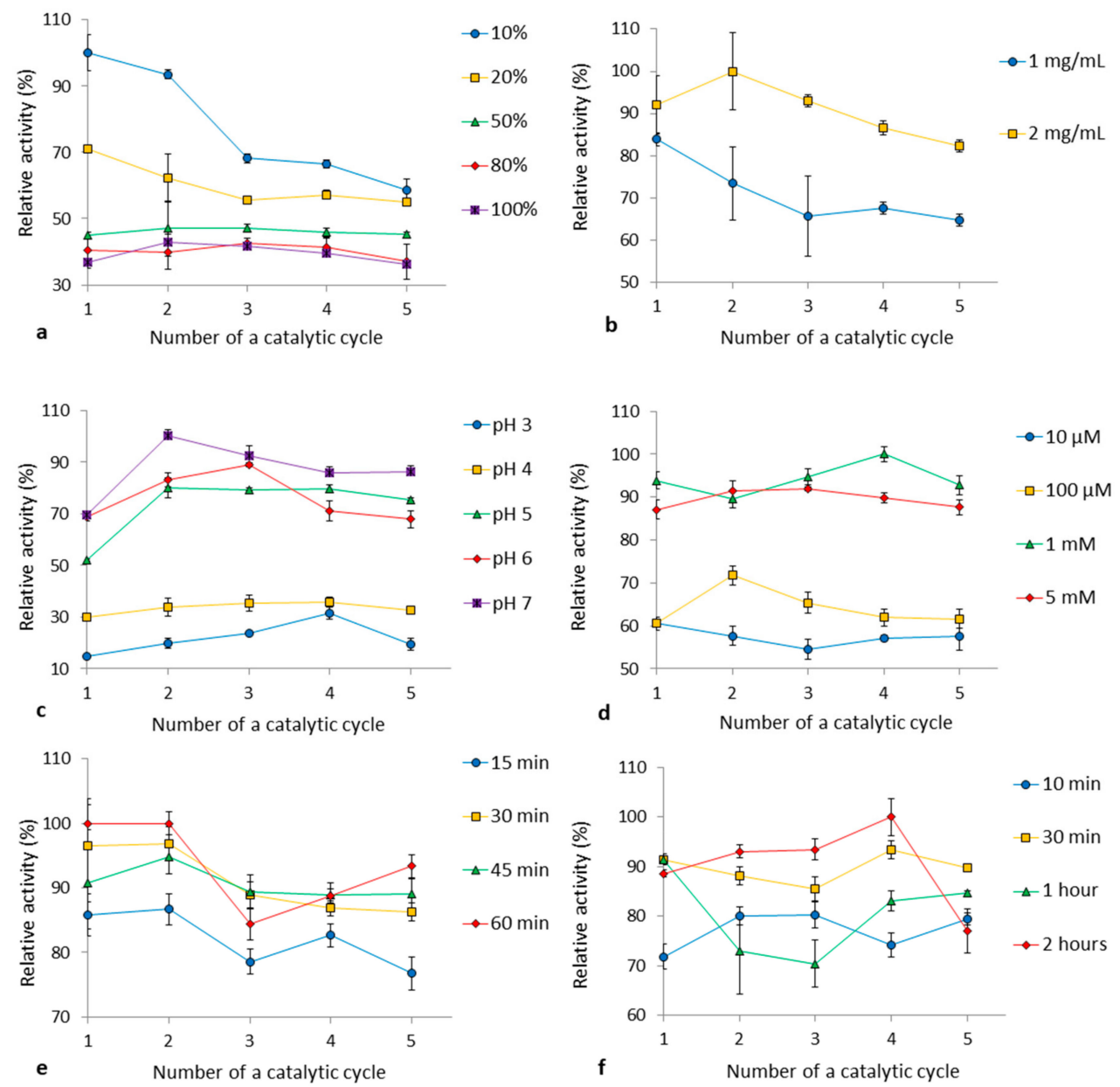

Figure 3. Parameters influencing laccase immobilization-concentration McIlvaine's buffer solution (a) (30-min oxidation with $1 \mathrm{mM} \mathrm{NaIO}_{4}, 1$-h immobilization using $1 \mathrm{mg} / \mathrm{mL}$ stock solution at $\mathrm{pH}$ 4), concentration of laccase solution; (b) (30-min oxidation with $1 \mathrm{mM} \mathrm{NaIO}_{4}, 1$-h immobilization using $1 \mathrm{mg} / \mathrm{mL}$ stock solution at $20 \% \mathrm{pH} 4$ buffer), $\mathrm{pH}$; (c) (30-min oxidation with $1 \mathrm{mM} \mathrm{NaIO}_{4}, 1-\mathrm{h}$ immobilization using $2 \mathrm{mg} / \mathrm{mL}$ stock solution at $20 \% \mathrm{pH} 4$ buffer), concentration of sodium periodate; (d) (30-min oxidation, 1-h immobilization using $2 \mathrm{mg} / \mathrm{mL}$ stock solution at $20 \% \mathrm{pH} 7 \mathrm{buffer}$ ), oxidation; (e) (oxidation with $1 \mathrm{mM} \mathrm{NaIO}_{4}, 1-\mathrm{h}$ immobilization using $2 \mathrm{mg} / \mathrm{mL}$ stock solution at $20 \% \mathrm{pH} 7 \mathrm{buffer}$ ), and immobilization time; and (f) (30-min oxidation with $1 \mathrm{mM} \mathrm{NaIO}_{4}$, immobilization using $2 \mathrm{mg} / \mathrm{mL}$ stock solution at $20 \% \mathrm{pH} 7$ buffer). 
3.2.2. Effect of Concentration of $\mathrm{NaIO}_{4}$ and Oxidation Time on the Immobilization of Laccase onto PA/PEI Nanofibers

In this study, we tested four different concentrations of the $\mathrm{NaIO}_{4}$ oxidizing agent and four reaction times in order to assess the optimal combination giving the highest activity and allowing for reuse of the immobilized laccase. As in the study of reference [25], the most appropriate concentration proved to be $1 \mathrm{mM}$ (Figure $3 \mathrm{~d}$ ) as it provides a sufficient oxidation time of ca. $30 \mathrm{~min}$ (Figure 3e).

\subsubsection{Effect of Immobilization Time on the Immobilization of Laccase onto PA/PEI Nanofibers}

There was no significant difference in immobilized laccase activity in samples taken between $10 \mathrm{~min}$ and $2 \mathrm{~h}$ of immobilization time (Figure 3f). Overall, however, the best combination of activity and stability was achieved at $30 \mathrm{~min}$.

\subsection{Summary of the Optimal Immobilization Process}

There were statistically significant differences between group means of all studied parameters as determined by one-way ANOVA (buffer concentration: $F(4.20)=16.69, p=3.68 \times 10^{-6} ; \mathrm{pH}: F(4.20)$ $=50.95, p=3.28 \times 10^{-10}$; concentration of $\mathrm{NaIO}_{4}: F(3,16)=148.76, p=6.77 \times 10^{-12}$; oxidation time: $F(3,16)=4.85, p=0.0138$; immobilization time: $F(3,16)=5.13, p=0.0112)$. Figure 4 illustrates the best results based on the multiple comparison test.

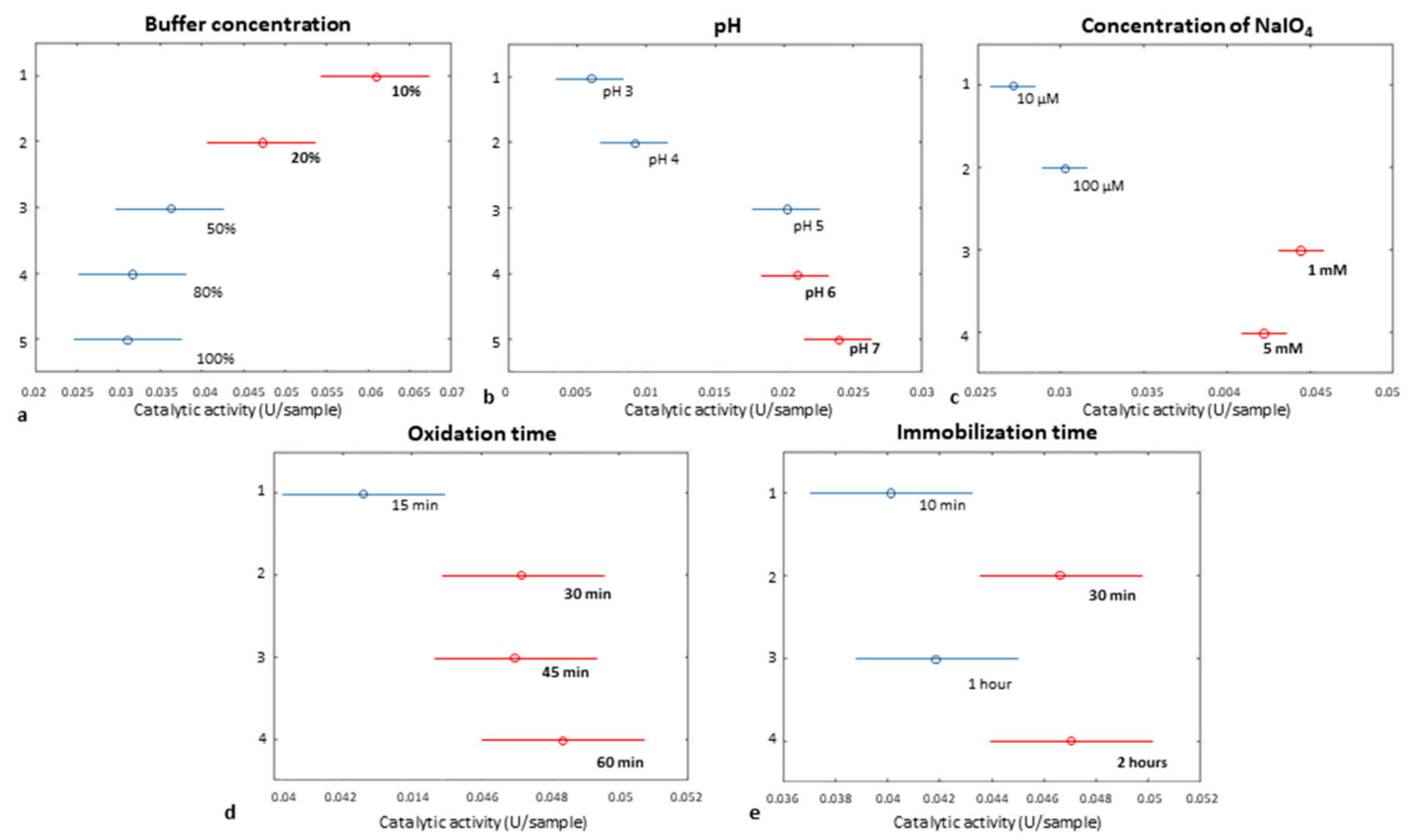

Figure 4. Statistical analysis of studied immobilization parameters using the multiple comparison test: optimal buffer concentration $10 \%$ and $20 \%$ (a); optimal pH 6 and 7 (b); optimal concentration of $\mathrm{NaIO}_{4}$ $1 \mathrm{mM}$ and $5 \mathrm{mM}(\mathbf{c})$; optimal oxidation time 30, 45, and $60 \mathrm{~min}(\mathbf{d})$; and optimal immobilization time $30 \mathrm{~min}$ and $2 \mathrm{~h}(\mathbf{e})$.

Overall, the optimal immobilization process required a $10 \mathrm{mg} / \mathrm{mL}$ laccase stock solution to be oxidized via $1 \mathrm{mM} \mathrm{NaIO}_{4}$ for $30 \mathrm{~min}$ at $4{ }^{\circ} \mathrm{C}$. Subsequently, any residual oxidizing agent was removed using gel filtration (PD MiniTrap G-25, centrifugation for $2 \mathrm{~min}$ at $2400 \mathrm{rpm}$ ). The oxidized laccase solution was diluted with $20 \%$ McIlvaine's buffer $\mathrm{pH} 7$ to produce a solution with a concentration of $2 \mathrm{mg} / \mathrm{mL}$ (Figure $3 \mathrm{~b}$ ). Next, the PA/PEI nanofiber samples (1.5 cm diameter) were submerged separately into $300 \mu \mathrm{L}$ of laccase solution and shaken at $4{ }^{\circ} \mathrm{C}$ in an orbital shaker at $150 \mathrm{rpm}$ for $30 \mathrm{~min}$. Finally, the samples were washed with McIlvaine's buffer in order to remove all unattached enzyme molecules. The activity yield of optimized samples was $10.153 \pm 1.628 \%$. 


\subsection{Storage Stability and Reusability of Immobilized Laccase}

The PA/PEI-laccase samples retained more than $52 \%$ of initial activity after 30 days of storage (Figure 5). This is comparable to our previous results with polyamide/chitosan (20\% activity loss after 14 days of storage) and pristine PA6 (50\% activity loss after 30 days of storage) as a nanofiber support $[15,16]$, though the optimal buffer in the current study was exchanged for the less profitable DIW. Reuse of PA/PEI-laccase samples was excellent, reaching up to $100 \%$ of initial activity after five rounds of ABTS oxidation (Figure 3). This indicates a very high level of stability compared to the literature in references [26,27].

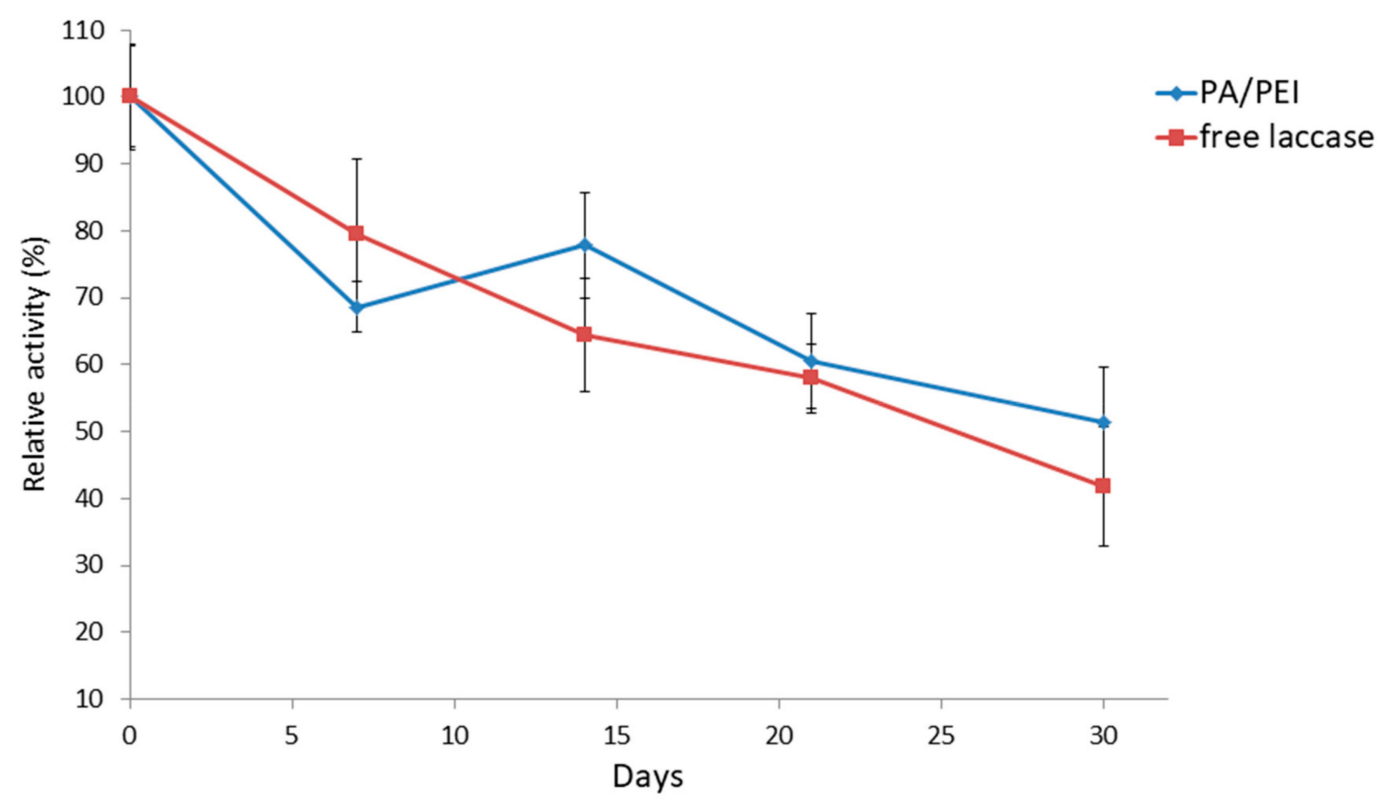

Figure 5. Storage stability of free and immobilized laccase. PA/PEI nanofibers loaded with immobilized laccase were incubated deionized water at $4{ }^{\circ} \mathrm{C}$. Free laccase solution was stored under the same conditions for comparison with the immobilized laccase.

\subsection{EDCs Degradation}

In general, PA/PEI-laccase removal efficiency of a mixture of BPA, EE2, TCS, and DCF was higher in DIW than wastewater effluent, reaching the highest efficiency in elimination of TCS (73.6\%), followed by EE2 $(47.3 \%)$, BPA $(27.9 \%)$, and DCF $(17.5 \%)$. Although EDC removal in real wastewater effluent proved somewhat less efficient, the PA/PEI-laccase samples were still successful, considering the degree of pollution and the presence of highly concentrated ions (especially chloride) that could negatively affect enzyme activity (Table 1) [28-30]. When using wastewater infused with Mcllvaine's buffer, however, PA/PEI-laccase degradation efficiency achieved a similar level of efficiency to those in DIW (Figure 6). Although the addition of buffer enhanced degradation efficiency, this step is not necessary in final applications from an economical point of view. 


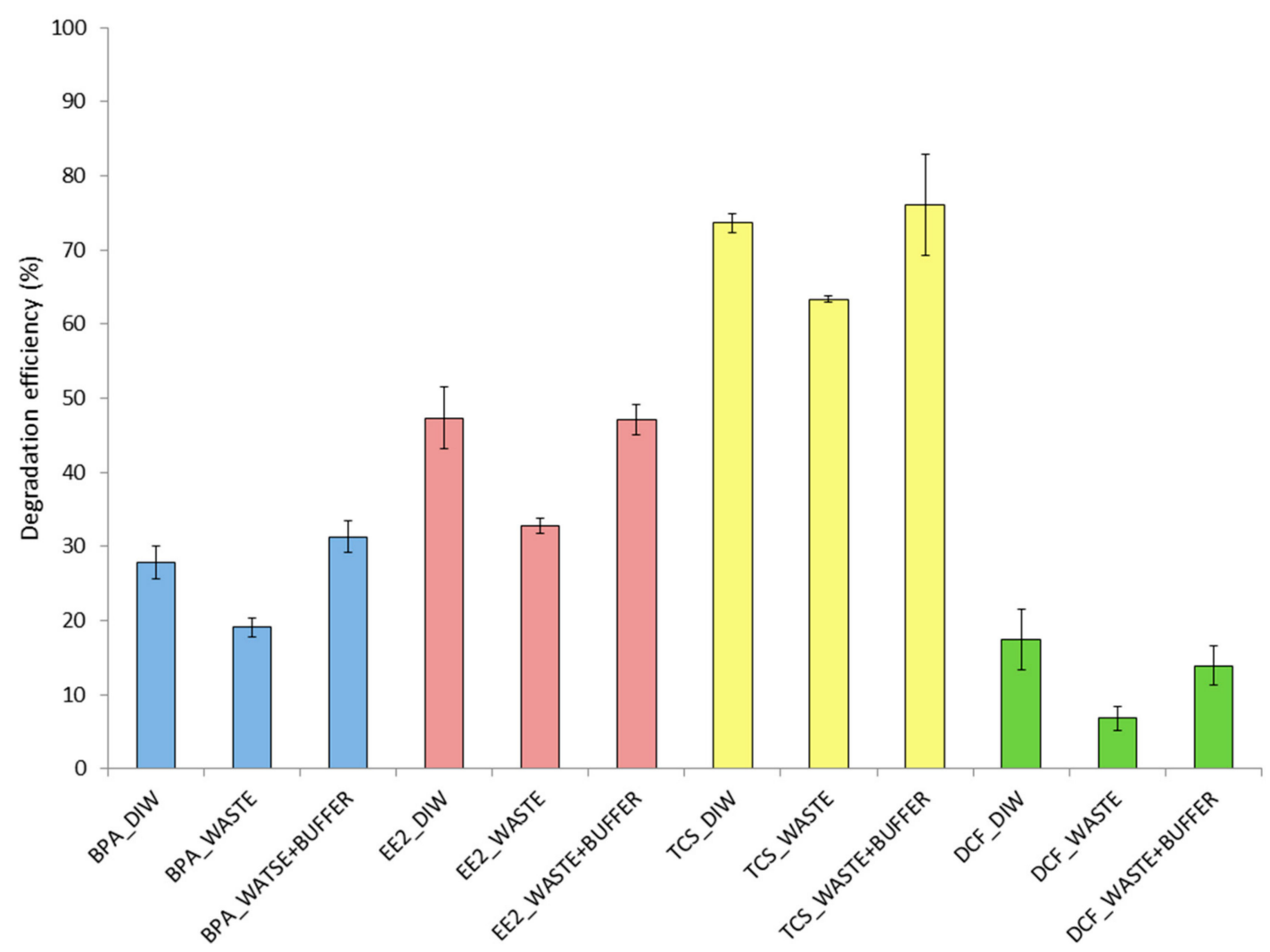

Figure 6. Degradation efficiency of immobilized laccase (PA/PEI-laccase) towards a mixture of $10 \mathrm{mg} / \mathrm{mL}$ of bisphenol A (BPA), $17 \alpha$-ethinylestradiol (EE2), triclosan (TCS), and diclofenac (DCF), in deionized water (DIW), wastewater effluent (WASTE), and wastewater infused with $2.5 \%(v / v)$ of McIlvaine's buffer of pH 7 (WASTE + BUFFER).

Degradation of similar xenobiotics using immobilized laccase has been described in a number of studies [31]. For example, reference [32] used laccase from C. unicolor (12 U/5 mL) immobilized onto porous silica beads to eliminate around $90 \%$ of BPA $(50 \mu \mathrm{M})$ within $60 \mathrm{~min}$ of incubation, with similarly rapid BPA degradation also reported in other studies [33,34]. García-Morales et al. [35] extended the number of micropollutants by including EE2, TCS, and nonylphenol, and this mixture was eliminated within $5 \mathrm{~h}$ using $100 \mathrm{U} / \mathrm{L}$ laccase. Although these studies appear to have been more successful at EDC degradation, none can be compared directly to our research as most of the authors were operating in a buffer system using a highly concentrated laccase source, which is incomparable to our stable PA/PEI-laccase tested in real wastewater infused with buffer.

\section{Conclusions}

Conventional wastewater treatment methods are insufficient for the complete reduction of some pollutants, and especially endocrine-disrupting chemicals. The current strategy of general wastewater treatment is based mainly on two alternative processes: ozonation and treatment with powdered activated carbon. Alternative technologies involve nanofiltration, reverse osmosis, and biological or enzymatic treatment.

We developed a novel nanofibrous material suitable for immobilization of a range of biomolecules. The PA/PEI nanofibers proved robust, stable in aquatic environments, and safe to handle compared to the more often used controversial nanoparticles. Our simple method, based on the blending of PA6 with branched PEI, guaranteed the availability of multiple primary amino groups. Further, immobilization of $T$. versicolor laccase onto the PA/PEI nanofibers provided excellent results, with the laccase remaining both highly active and stable. Most importantly, the PA/PEI-laccase samples 
proved successful at degrading a mixture of four highly concentrated EDC (BPA, EE2, TCS, and DCF) in real wastewater effluent.

We have proved that nanofibers represent a promising material, because they are safe and easy to prepare. Their major advantage over particle- or nanoparticle-matrices is their ability to be handled as textiles while possessing enough immobilization capacity to strongly attach laccase, which gives them great potential for use as enzymatically activated filters in water treatment technologies.

Author Contributions: Conceptualization, M.M.; methodology, M.M., V.N., and H.T.; investigation, M.M. and M.S.; resources, H.T.; writing — original draft preparation, M.M., V.N., and H.T.; writing—review and editing, M.M. and H.T.; supervision, M.M. and M.R.; project administration, M.R.; funding acquisition, M.R. All authors have read and agreed to the published version of the manuscript.

Funding: This research was supported through the Technology Agency of the Czech Republic (projects FV10054, TH02020786 and TH02030858) and by the MŠMT of the Czech Republic and the European Structural and Investment Funds in the frames of Operational Programme Research, Development and Education-project Hybrid Materials for Hierarchical Structures 'HyHi' (CZ.02.1.01/0.0/0.0/16_019/ 0000843). The research of M. Maryšková was supported by the MŠMT of the Czech Republic through the SGS project no. 21338/115 of the Technical University of Liberec.

Acknowledgments: I would like to express our gratitude towards Pavel Kejzlar for processing the SEM images.

Conflicts of Interest: The authors declare no conflict of interest. The funders had no role in the design of the study; in the collection, analyses, or interpretation of data; in the writing of the manuscript; or in the decision to publish the results.

\section{References}

1. López-Pacheco, I.Y.; Silva-Núñez, A.; Salinas-Salazar, C.; Arévalo-Gallegos, A.; Lizarazo-Holguin, L.A.; Barceló, D.; Iqbal, H.M.N.; Parra-Saldívar, R. Anthropogenic contaminants of high concern: Existence in water resources and their adverse effects. Sci. Total Environ. 2019, 690, 1068-1088. [CrossRef] [PubMed]

2. Majumder, A.; Gupta, B.; Gupta, A.K. Pharmaceutically active compounds in aqueous environment: A status, toxicity and insights of remediation. Environ. Res. 2019, 176, 108542. [CrossRef] [PubMed]

3. Cunningham, V.L.; Binks, S.P.; Olson, M.J. Human health risk assessment from the presence of human pharmaceuticals in the aquatic environment. Regul. Toxicol. Pharmacol. 2009, 53, 39-45. [CrossRef] [PubMed]

4. Diamanti-Kandarakis, E.; Bourguignon, J.-P.; Giudice, L.C.; Hauser, R.; Prins, G.S.; Soto, A.M.; Zoeller, R.T.; Gore, A.C. Endocrine-disrupting chemicals: an Endocrine Society scientific statement. Endocr. Rev. 2009, 30, 293-342. [CrossRef] [PubMed]

5. Hai, F.I.; Yamamoto, K.; Fukushi, K. Hybrid treatment systems for dye wastewater. Crit. Rev. Environ. Sci. Technol. 2007, 37, 315-377. [CrossRef]

6. Sharma, B.; Dangi, A.K.; Shukla, P. Contemporary enzyme based technologies for bioremediation: A review. J. Environ. Manag. 2018, 210, 10-22. [CrossRef]

7. Xu, R.; Tang, R.; Zhou, Q.; Li, F.; Zhang, B. Enhancement of catalytic activity of immobilized laccase for diclofenac biodegradation by carbon nanotubes. Chem. Eng. J. 2015, 262, 88-95. [CrossRef]

8. Costa, J.B.; Lima, M.J.; Sampaio, M.J.; Neves, M.C.; Faria, J.L.; Morales-Torres, S.; Tavares, A.P.M.; Silva, C.G. Enhanced biocatalytic sustainability of laccase by immobilization on functionalized carbon nanotubes/polysulfone membranes. Chem. Eng. J. 2019, 355, 974-985. [CrossRef]

9. Alver, E.; Metin, A.Ü. Chitosan based metal-chelated copolymer nanoparticles: Laccase immobilization and phenol degradation studies. Int. Biodeterior. Biodegrad. 2017, 125, 235-242. [CrossRef]

10. Rotková, J.; Šuláková, R.; Korecká, L.; Zdražilová, P.; Jandová, M.; Lenfeld, J.; Horák, D.; Bílková, Z. Laccase immobilized on magnetic carriers for biotechnology applications. J. Magn. Magn. Mater. 2009, 321, 1335-1340. [CrossRef]

11. Kadam, A.A.; Jang, J.; Jee, S.C.; Sung, J.-S.; Lee, D.S. Chitosan-functionalized supermagnetic halloysite nanotubes for covalent laccase immobilization. Carbohydr. Polym. 2018, 194, 208-216. [CrossRef] [PubMed]

12. Wen, X.; Zeng, Z.; Du, C.; Huang, D.; Zeng, G.; Xiao, R.; Lai, C.; Xu, P.; Zhang, C.; Wan, J.; et al. Immobilized laccase on bentonite-derived mesoporous materials for removal of tetracycline. Chemosphere 2019, 222, 865-871. [CrossRef] 
13. Zdarta, J.; Antecka, K.; Frankowski, R.; Zgoła-Grześkowiak, A.; Ehrlich, H.; Jesionowski, T. The effect of operational parameters on the biodegradation of bisphenols by Trametes versicolor laccase immobilized on Hippospongia communis spongin scaffolds. Sci. Total Environ. 2018, 615, 784-795. [CrossRef] [PubMed]

14. Kashefi, S.; Borghei, S.M.; Mahmoodi, N.M. Covalently immobilized laccase onto graphene oxide nanosheets: Preparation, characterization, and biodegradation of azo dyes in colored wastewater. J. Mol. Liq. 2019, 276, 153-162. [CrossRef]

15. Maryšková, M.; Ardao, I.; García-González, C.A.; Martinová, L.; Rotková, J.; Ševců, A. Polyamide 6/chitosan nanofibers as support for the immobilization of Trametes versicolor laccase for the elimination of endocrine disrupting chemicals. Enzym. Microb. Technol. 2016, 89, 31-38. [CrossRef] [PubMed]

16. Maryskova, M.; Rysova, M.; Novotny, V.; Sevcu, A. Polyamide-Laccase Nanofiber Membrane for Degradation of Endocrine-Disrupting Bisphenol A, $17 \alpha$-ethinylestradiol, and Triclosan. Polymers 2019, 11, 1560. [CrossRef]

17. Arıca, M.Y.; Altıntas, B.; Bayramoğlu, G. Immobilization of laccase onto spacer-arm attached non-porous poly(GMA/EGDMA) beads: Application for textile dye degradation. Bioresour. Technol. 2009, 100, 665-669. [CrossRef] [PubMed]

18. Zhu, W.; Liu, L.; Liao, Q.; Chen, X.; Qian, Z.; Shen, J.; Liang, J.; Yao, J. Functionalization of cellulose with hyperbranched polyethylenimine for selective dye adsorption and separation. Cellulose 2016, 23, 3785-3797. [CrossRef]

19. An, G.S.; Choi, S.W.; Kim, T.G.; Shin, J.R.; Kim, Y.-I.; Choi, S.-C.; Jung, Y.-G. Amino-functionalization of colloidal alumina particles for enhancement of the infiltration behavior in a silica-based ceramic core. Ceram. Int. 2017, 43, 157-161. [CrossRef]

20. Hartwig, A.; Mulder, M.; Smolders, C.A. Surface amination of poly(acrylonitrile). Adv. Colloid Interface Sci. 1994, 52, 65-78. [CrossRef]

21. Hassani, T.; Ba, S.; Cabana, H. Formation of enzyme polymer engineered structure for laccase and cross-linked laccase aggregates stabilization. Bioresour. Technol. 2013, 128, 640-645. [CrossRef] [PubMed]

22. Choi-Rhee, E.; Schulman, H.; Cronan, J.E. Promiscuous protein biotinylation by Escherichia coli biotin protein ligase. Protein Sci. 2004, 13, 3043-3050. [CrossRef] [PubMed]

23. O'Shannessy, D.J.; Hoffman, W.L. Site-directed immobilization of glycoproteins on hydrazide-containing solid supports. Biotechnol. Appl. Biochem. 1987, 9, 488-496. [CrossRef] [PubMed]

24. Bioconjugate Techniques, 3rd Edition. Available online: https://www.elsevier.com/books/bioconjugatetechniques/hermanson/978-0-12-382239-0 (accessed on 19 October 2018).

25. Jolivalt, C.; Brenon, S.; Caminade, E.; Mougin, C.; Pontié, M. Immobilization of laccase from Trametes versicolor on a modified PVDF microfiltration membrane: characterization of the grafted support and application in removing a phenylurea pesticide in wastewater. J. Membr. Sci. 2000, 180, 103-113. [CrossRef]

26. Li, G.; Nandgaonkar, A.G.; Wang, Q.; Zhang, J.; Krause, W.E.; Wei, Q.; Lucia, L.A. Laccase-immobilized bacterial cellulose/TiO2 functionalized composite membranes: Evaluation for photo- and bio-catalytic dye degradation. J. Membr. Sci. 2017, 525, 89-98. [CrossRef]

27. Saravanakumar, T.; Park, H.-S.; Mo, A.-Y.; Choi, M.-S.; Kim, D.-H.; Park, S.-M. Detoxification of furanic and phenolic lignocellulose derived inhibitors of yeast using laccase immobilized on bacterial cellulosic nanofibers. J. Mol. Catal. B Enzym. 2016, 134, 196-205. [CrossRef]

28. Kepp, K.P. Halide binding and inhibition of laccase copper clusters: the role of reorganization energy. Inorg. Chem. 2015, 54, 476-483. [CrossRef]

29. Chapple, A.; Nguyen, L.N.; Hai, F.I.; Dosseto, A.; Rashid, M.H.-O.; Oh, S.; Price, W.E.; Nghiem, L.D. Impact of inorganic salts on degradation of bisphenol A and diclofenac by crude extracellular enzyme from Pleurotus ostreatus. Biocatal. Biotransform. 2019, 37, 10-17. [CrossRef]

30. Raseda, N.; Hong, S.; Kwon, O.Y.; Ryu, K. Kinetic evidence for the interactive inhibition of laccase from Trametes versicolor by $\mathrm{pH}$ and chloride. J. Microbiol. Biotechnol. 2014, 24, 1673-1678. [CrossRef]

31. Nair, R.R.; Demarche, P.; Agathos, S.N. Formulation and characterization of an immobilized laccase biocatalyst and its application to eliminate organic micropollutants in wastewater. New Biotechnol. 2013, 30, 814-823. [CrossRef]

32. Songulashvili, G.; Jimenéz-Tobón, G.A.; Jaspers, C.; Penninckx, M.J. Immobilized laccase of Cerrena unicolor for elimination of endocrine disruptor micropollutants. Fungal Biol. 2012, 116, 883-889. [CrossRef] [PubMed] 
33. Hongyan, L.; Zexiong, Z.; Shiwei, X.; He, X.; Yinian, Z.; Haiyun, L.; Zhongsheng, Y. Study on transformation and degradation of bisphenol A by Trametes versicolor laccase and simulation of molecular docking. Chemosphere 2019, 224, 743-750. [CrossRef] [PubMed]

34. Olajuyigbe, F.M.; Adetuyi, O.Y.; Fatokun, C.O. Characterization of free and immobilized laccase from Cyberlindnera fabianii and application in degradation of bisphenol A. Int. J. Biol. Macromol. 2019, 125, 856-864. [CrossRef] [PubMed]

35. García-Morales, R.; García-García, A.; Orona-Navar, C.; Osma, J.F.; Nigam, K.D.P.; Ornelas-Soto, N. Biotransformation of emerging pollutants in groundwater by laccase from P. sanguineus CS43 immobilized onto titania nanoparticles. J. Environ. Chem. Eng. 2018, 6, 710-717. [CrossRef]

C 2020 by the authors. Licensee MDPI, Basel, Switzerland. This article is an open access article distributed under the terms and conditions of the Creative Commons Attribution (CC BY) license (http://creativecommons.org/licenses/by/4.0/). 